\title{
Lokakarya Pengembangan Media Pembelajaran Interaktif dalam Pembelajaran Daring di Sekolah Dasar
}

\author{
Prihantini*1, Tyara $^{2}$, Dinila ${ }^{3}$, Puspitasari $^{4}$, Khairunnisa $^{5}$ \\ 1,2,3,4,5 Program Studi S1 PGSD, UPI Cibiru \\ *e-mail: prihantini@upi.edu ${ }^{1}{ }_{2}$ tyara.ratna@upi.edu ${ }^{2}{ }_{2}$ hanadinila@upi.edu $^{3}$ \\ evipuspitasari1999@upi.edu ${ }^{4}$, khrnnsa@upi.edu $^{5}$
}

\begin{abstract}
Abstrak
Terjadinya pandemi covid-19 berdampak pembelajaran di sekolah tidak dapat dilaksanakan secara tatap muka dan harus melalui pembelajaran jarak jauh dalam jaringan (PJJ-daring). Pelaksanaan PJJdaring juga ditempuh oleh Sekolah Dasar Islam Terpadu (SDIT) Insan Teladan, namun demikian hasil observasi dan wawancara dengan kepala sekolah dan guru-guru diperoleh informasi bahwa sekolah selama melaksanakan PJJ-Daring belum menggunakan media pembelajaran interaktif. Permasalahan ini disebabkan guru-guru belum terlatih membuat dan menggunakan media pembelajaran interaktif, hal ini menunjukkan bahwa guru-guru SDIT Insan Teladan membutuhkan fasilitasi bimbingan teknis pembuatan dan penggunaan media pembelajaran interaktif. Faktor lain yang perlu dipertimbangkan oleh sekolah untuk mengembangkan media pembelajaran interaktif adalah dalam PJJ-daring, peserta didik tidak selalu didampingi oleh orang tua karena sebagian besar orang tua peserta didik adalah karyawan atau karyawati. Berdasarkan permasalahan tersebut maka Tim Pengabdian termotivasi melaksanakan lokakarya pembuatan dan penggunaan media pembelajaran interaktif yang mudah dan praktis bagi guru-guru SDIT Insan Teladan untuk dapat dimanfaatkan dalam PJJ-daring. Tujuan lokakarya adalah untuk melatih guruguru membuat dan menggunakan media pembelajaran interaktif berbasis teknologi informasi dan komunikasi (TIK) yang mudah diterapkan untuk PJJ-daring. Metode pelaksanaan kegiatan ditempuh melalui tahap observasi dan wawancara, rapat koordinasi dan needs assessment, lokakarya, dan follow up. Hasil dari kegiatan lokakarya, nilai pretest dan posttest menunjukkan adanya peningkatan perolehan rata-rata nilai, yakni rata-rata nilai pretest 54,74 dan postest mencapai 75,71. Hal ini dapat disimpulkan bahwa melalui lokakarya pengembangan media pembelajaran interaktif, guru-guru SDIT Insan Teladan mampu mengembangkan media pembelajaran interaktif dalam bentuk powerpoint interaktif, lembar kerja peserta didik (LKPD) interaktif, dan video animasi powtoon.
\end{abstract}

Kata kunci: lokakarya, media pembelajaran interaktif, pembelajaran jarak jauh dalam jaringan

\section{Abstract}

The occurrence of the Covid-19 pandemic has an impact that learning in schools cannot be carried out face-to-face and must be through online distance learning (ODL). The implementation of ODL is also carried out by Insan Teladan Integrated Islamic Elementary School (SDIT Insan Teladan), however, the results of observations and interviews with school principals and teachers obtained information that during the implementation of ODL the teachers have not used interactive learning media. This problem is because the teachers have not been trained to create and use interactive learning media, this shows that SDIT Insan Teladan teachers need technical guidance facilitation to create and use interactive learning media. Another factor that needs to be considered by schools to develop interactive learning media is in ODL, students are not always accompanied by parents because most of the parents of students are employees. Based on these problems, the Community Service Team was motivated to carry out workshops on the creation and use of interactive learning media that are easy and practical for SDIT Insan Teladan teachers to be used in ODL. The aim of the workshop is to train teachers to create and use interactive learning media based on information and communication technology (ICT) that are easy to implement for ODL. The method of implementing the workshop is through observation and interviews, coordination meetings and needs assessment, workshops, and follow-up. The results of the workshop activities, the pretest and posttest scores showed an increase in the average score, the average pretest score was 54.74 and the posttest was reaching 75.71. It can be concluded that through the interactive learning media development workshop, SDIT Insan Teladan teachers were able to develop interactive learning media in the form of interactive powerpoints, interactive student worksheets, and animated powtoon videos.

Keywords: interactive learning media, online distance learning, workshop 


\section{PENDAHULUAN}

Sekolah Dasar Islam Terpadu (SDIT) Insan Teladan berlokasi di Jalan Villa Bandung Indah, Cimekar Kecamatan Cileunyi Kabupaten Bandung, berdekatan dengan lokasi komplek Vila Bandung Indah. Jarak tempuh perjalanan menggunakan kendaraan umum dari Kampus UPI Cibiru ke lokasi sekolah membutuhkan waktu kurang lebih 20 menit. Hal ini salah satu faktor yang memotivasi tim untuk melaksanakan pengabdian ke sekolah tersebut sebagai wujud Tri Dharma Perguruan Tinggi. Peserta didik yang ada di sekolah ini sebagian besar berdomisili di Komplek Vila Bandung Indah dan rata-rata orang tuanya berlatar belakang sebagai karyawan atau karyawati. Jumlah rombongan belajar terdiri dari 13 rombel, kelas 1,2,3,5,6 masing-masing memiliki dua rombongan belajar dan kelas 4 ada tiga rombongan belajar, dengan jumlah peserta didik seluruhnya 261 peserta didik. Jumlah guru seluruhnya ada 19 orang, dengan latar belakang Sarjana (S1), namun demikian tidak semuanya berlatar belakang S1 Kependidikan. Sarana prasarana SDIT Insan Teladan dapat dikatakan memenuhi standar pelayanan minimal, jumlah ruang kelas dan prasarana fisik lainnya lengkap demikian pula sarana jaringan internet telah tersedia.

Observasi sekolah yang dilaksanakan pada tanggal 25-26 Februari 2021, ketika wawancara dengan kepala sekolah diperoleh informasi bahwa sekolah membutuhkan fasilitasi bimbingan teknis pembuatan media pembelajaran interaktif. Tindak lanjut dari hasil wawancara tersebut maka pada tanggal 8 Maret 2021 dilaksanakan rapat kordinasi dengan guru-guru untuk merencanakan pelaksanakan lokakarya pembelajaran interaktif dan membagikan instrument needs assessment materi lokakarya melalui google form. Kebutuhan tentang kemampuan membuat media pembelajaran interaktif diakui oleh semua guru dengan terjadinya pandemi covid-19, karena pembelajaran tidak dapat dilaksanakan secara tatap muka dan harus melalui pembelajaran jarak jauh dalam jaringan (PJJ-daring). Latar belakang orang tua peserta didik sebagian besar karyawan atau karyawati perlu menjadi pertimbangan ketika sekolah melaksanakan PPJ-daring, karena peserta didik belajar di rumah tidak selalu didampingi oleh orang tuanya. Hasil rapat koordinasi juga diperoleh simpulan bahwa selama PJJ-daring guru belum menggunakan media pembelajaran interaktif yang dibuat sendiri dengan alasan belum mengenal teknik pembuatannya.

Media pembelajaran PJJ daring bagi peserta didik SD tentu saja perlu ditampilkan lebih menarik dan dapat memperjelas pemahaman peserta didik, baik tentang materi pembelajaran maupun tugas dalam bentuk lembar kerja peserta didik (LKPD) sesuai karakteristik perkembangannya. Peserta didik SD yang berusia sekitar 7-12 tahun berada pada tahap perkembangan operasional konkret, pada usia ini terjadi operasi mental yaitu sebagai kemampuan untuk mengimajinasikan secara konkret kosekuensi yang akan terjadi [1]. Pembelajaran merupakan proses komunikasi antara pembelajar, pengajar, dan bahan ajar [2], ketika harus dilaksanakan PJJ-daring dibutuhkan media yang merupakan alat komunikasi yang membawa pesan dari sumber ke penerima [3]. Hakikatnya media pembelajaran merupakan wahana untuk menyampaikan pesan atau informasi dari sumber pesan diteruskan pada penerima [4]. Media sebagai salah satu komponen pembelajaran memiliki peranan penting dalam mencapai sebuah tujuan belajar [5], karena dengan menggunakan media dapat memberikan pengalaman yang berbdeda dan bervariasi sehingga merangsang minat peserta didik untuk belajar [3]. Urgensi media pembelajaran sebagai salah satu komponen utama pembelajaran karena dapat memperjelas pengalaman belajar yang abstrak menjadi konkret. Media pembelajaran interaktif yang strategis digunakan pada PJJ-daring antara lain melalui powerpoint interaktif dan video animasi. Dua jenis media interaktif berbasis teknologi informasi dan komunikasi (TIK) ini selain mudah pembuatannya juga praktis penggunaannya.

Hasil penelitian terdahulu telah membuktikan pengaruh positif dari penggunaan media pembelajaran interaktif, baik power point interaktif maupun video animasi. Kesimpulan hasil penelitian [6], bahwa dengan media pembelajaran interaktif maka peserta didik akan lebih mudah dan cepat memahami materi pelajaran, selain itu proses pembelajaran akan lebih menarik dan menyenangkan. Hasil penelitian lain tentang penggunaan media pembelajaran power point disimpulkan bahwa power point efektif digunakan dalam pembelajaran materi 
animalia kelas VIII di SMP Negeri 1 Pandak [7]. Media interaktif power point dapat dikombinasikan dengan animasi, hal ini telah dibuktikan melalui penelitian [8],

pemanfaatan media pembelajaran powerpoint berbasis animasi dapat meningkatan motivasi belajar peserta didik dan hasil belajar peserta didik pada standar kompetensi membuat dan menjaga kearsipan untuk menjamin integritas. Penelitian penggunaan video dalam pembelajaran [9] dibuktikan bahwa terdapat perbedaan yang signifikan hasil belajar peserta didik antara sebelum dan sesudah menggunakan video pembelajaran. Tidak hanya power point yang dapat dikombinasikan dengan animasi, video juga dapat dikombinasikan dengan animasi. Hal ini telah terbukti melalui penelitian [10] terdapat perbedaan signifikan skor motivasi belajar dan karakter kerja keras peserta didik antara sebelum dan sesudah menggunakan media video animasi dalam pembelajaran.

Permasalahan yang terjadi di SDIT Insan Teladan dapat disimpulkan, pertama, guru-guru SDIT Insan Teladan membutuhkan pelatihan untuk membuat media pembelajaran interaktif dengan memanfaatkan laptop dan jaringan yang tersedia, karena setiap guru telah memiliki laptop dan wajib hadir ke sekolah setiap hari untuk melaksanakan pembelajaran daring dari sekolah. Kedua, guru-guru belum pernah menerima atau mengikuti pelatihan pembuatan media pembelajaran interaktif berbasis TIK, sehingga berdampak guru-guru SDIT Insan Teladan belum mengenal media pembelajaran interaktif yang mudah dibuat dan praktis digunakan. Permasalahan ini menjadi motivasi tim untuk melatih guru-guru mengembangkan media pembelajaran interaktif. Tujuan lokakarya adalah memberikan pelatihan teknis pembuatan dan penggunaan media pembelajaran interaktif kepada guru-guru SDIT Insan Teladan, yang pembuatan maupun penggunaannya mudah diterapkan.

\section{METODE}

Metode yang diterapkan dalam pengabdian untuk mencapai tujuan yang diharapkan ditempuh beberapa tahap kegiatan sebagai berikut.

\subsection{Observasi sekolah dan wawancara}

Observasi sekolah dilaksanakan pada tanggal 25-26 Februari 2021 bertujuan untuk memperoleh gambaran kondisi lingkungan sekolah dan melaksanakan wawancara kepada kepala sekolah. Hasil observasi diperoleh gambaran bahwa sarana prasarana sekolah lengkap, di sekolah telah tersedia jaringan internet, setiap guru telah terfasilitasi laptop. Informasi yang diperoleh dari wawancara bahwa guru-guru SDIT Insan Teladan dalam pelaksanaan PJJ-daring belum menggunakan media pembelajaran interaktif berbasis TIK dan masih menerapkan metode ceramah.

\subsection{Rapat Koordinasi dan needs assessment}

Rapat koordinasi dilaksanakan bertujuan agar usaha kerjasama dengan sekolah sinkron untuk menyediakan waktu tepat serta mengarahkan pelaksanaan menghasilkan suatu tindakan yang seragam dan harmonis pada sasaran yang telah ditentukan [11]. Needs assessment bertujuan untuk menganalisis fakta kebutuhan yang memampukan program mengembangkan sejumlah aktivitas untuk memenuhi kebutuhan riil klien [12]. Kesepakatan pelaksanaan dalam rapat, lokakarya dilaksanakan selama tiga hari, tanggal 30-31 Maret dan 1 April 2021, pelaksanaan secara luring karena lebih mengutamakan praktik membuat media interaktif dengan bimbingan teknis langsung. Kesepakatan tempat lokakarya di ruang kelas dan pelaksanaan tetap menerapkan protokol kesehatan, jumlah peserta 19 orang guru SD ditambah 1 orang kepala sekolah dan 1 orang pengurus yayasan yang membidangi pendidikan. Hasil needs assessment diperoleh simpulan bahwa guru-guru membutuhkan tiga materi yang mudah dan praktis, yaitu LKPD interaktif, power point interaktif, dan video animasi powtoon.

\subsection{Pelaksanaan Lokakarya}

Dipilih metode lokakarya karena melalui kegiatan ini peserta praktik langsung untuk menghasilkan produk atau menghasilkan karya berupa media pembelajaran interaktif berbasis TIK. Materi dalam lokakarya bersumber pada kebutuhan peserta, sebagaimana telah dilakukan 
melalui needs assessment disimpulkan bahwa materi lokakarya yang dibutuhkan peserta meliputi pembuatan powerpoint interaktif, video animasi powtoon, dan LKPD interaktif.

\subsection{Follow up}

Setelah pelaksanaan lokakarya dilaksanakan follow up kepada guru-guru agar mereka menyampaikan kesulitan ketika harus bekerja mandiri membuat media pembelajaran interaktif dan menggunakannya. Follow up ditempuh dengan menanyakan kepada guru tentang masalah yang dihadapi dalam pembuatan dan penggunaan media pembelajaran interaktif melalui whatsApp pribadi.

\section{HASIL DAN PEMBAHASAN}

Kegiatan lokakarya pengembangan media pembelajaran interaktif dalam pembelajaran daring di SDIT Insan Teladan terlaksana sesuai rencana. Peserta terdiri dari 19 guru, 1 orang kepala sekolah, dan 1 orang pengurus yayasan yang membidangi pendidikan. Aktivitas peserta dalam lokakarya 30 persen menyimak ceramah interaktif dan $70 \%$ praktik membuat karya media pembelajaran interaktif. Aktivitas lokakarya sebagaimana terlihat pada tabel 1 berikut.

Tabel 1. Aktivitas Pelaksanaan Lokakarya

\begin{tabular}{|c|c|c|c|}
\hline Hari ke & $\begin{array}{c}\text { Waktu } \\
\text { Pelaksanaan }\end{array}$ & Aktivitas & $\begin{array}{c}\text { Pelaksana/ } \\
\text { Pemateri }\end{array}$ \\
\hline \multirow[t]{4}{*}{$\begin{array}{c}1 \\
\text { (30 Maret } \\
2021)\end{array}$} & $12.30-12.45$ & $\begin{array}{c}\text { Pembukaan dan Penjelasan } \\
\text { Teknis Kegiatan }\end{array}$ & $\begin{array}{c}\text { Kepala SDIT } \\
\text { Insan Teladan } \\
\text { dan Prihantini }\end{array}$ \\
\hline & $12.45-13.15$ & Pre Test & Tim \\
\hline & $13.15-14.45$ & $\begin{array}{l}\text { Penjelasan materi dan praktik } \\
\text { membuat powerpoint interaktif }\end{array}$ & $\begin{array}{c}\text { Hana Septiana } \\
\text { danila dan Evi } \\
\text { Puspitasari }\end{array}$ \\
\hline & $14.45-15.00$ & Penguatan hasil karya peserta & Hana Septiana \\
\hline \multirow{3}{*}{$\begin{array}{c}2 \\
\text { (31 Maret } \\
\text { 2021) }\end{array}$} & $12.30-13.00$ & Review kegiatan hari pertama & Prihantini \\
\hline & $13.00-14.45$ & $\begin{array}{l}\text { Penjelasan materi dan praktik } \\
\text { membuat video animasi } \\
\text { powtoon }\end{array}$ & $\begin{array}{c}\text { Ratna Tyara dan } \\
\text { Khairunnisa }\end{array}$ \\
\hline & $14.45-15.00$ & Penguatan hasil karya peserta & Ratna Tyara \\
\hline \multirow{5}{*}{$\begin{array}{c}3 \\
\text { (1 April } \\
2021)\end{array}$} & $12.30-13.00$ & Review kegiatan hari kedua & Prihantini \\
\hline & $13.00-14.00$ & $\begin{array}{l}\text { Penjelasan materi dan praktik } \\
\text { membuat LKPD interaktif }\end{array}$ & Prihantini \\
\hline & $14.00-14.15$ & Penguatan hasil karya peserta & Prihantini \\
\hline & $14.15-14.45$ & Post Test & Tim \\
\hline & $14.45-15.00$ & Penutupan & $\begin{array}{c}\text { Kepala SDIT } \\
\text { Insan Teladan } \\
\text { dan Prihantini }\end{array}$ \\
\hline
\end{tabular}

Ciri dari lokakarya adalah peserta lebih banyak praktik untuk menghasilkan karya, sehingga kegiatan lokakarya para peserta lebih dominan bekerja dalam kelompok kecil untuk membuat karya sesuai penjelasan yang diberikan Pemateri. Aktivitas peserta sebagaimana terlihat pada gambar berikut. 


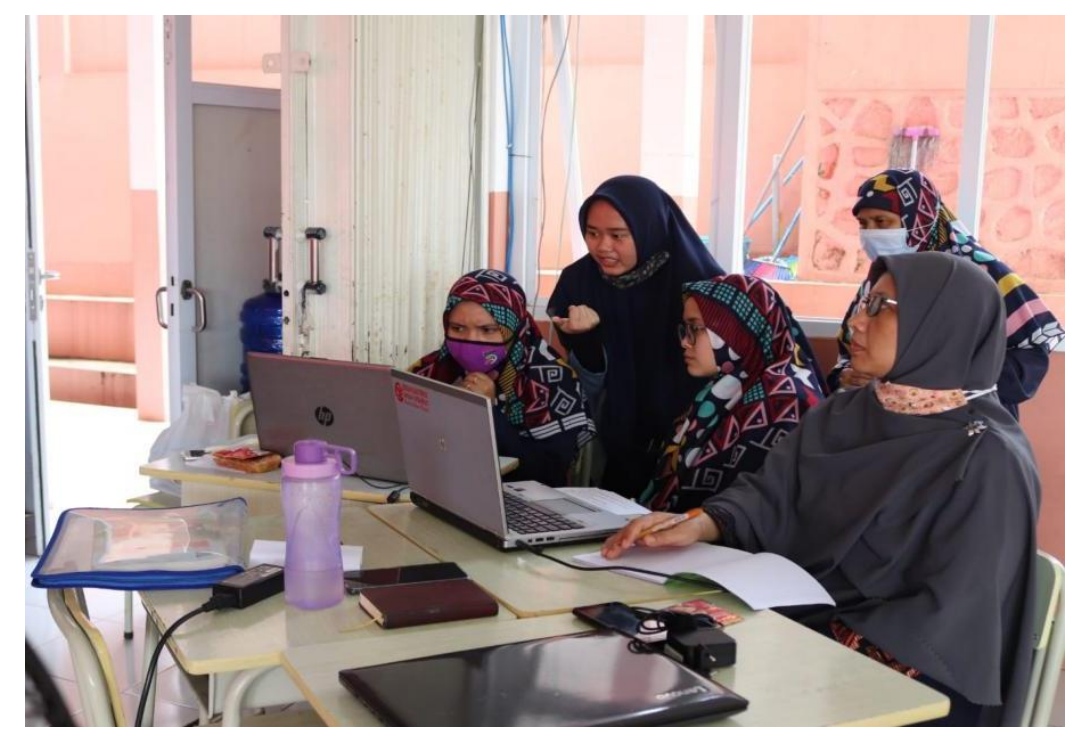

Gambar 1. Aktivitas Peserta Praktik Membuat Karya Media Pembelajaran Interaktif

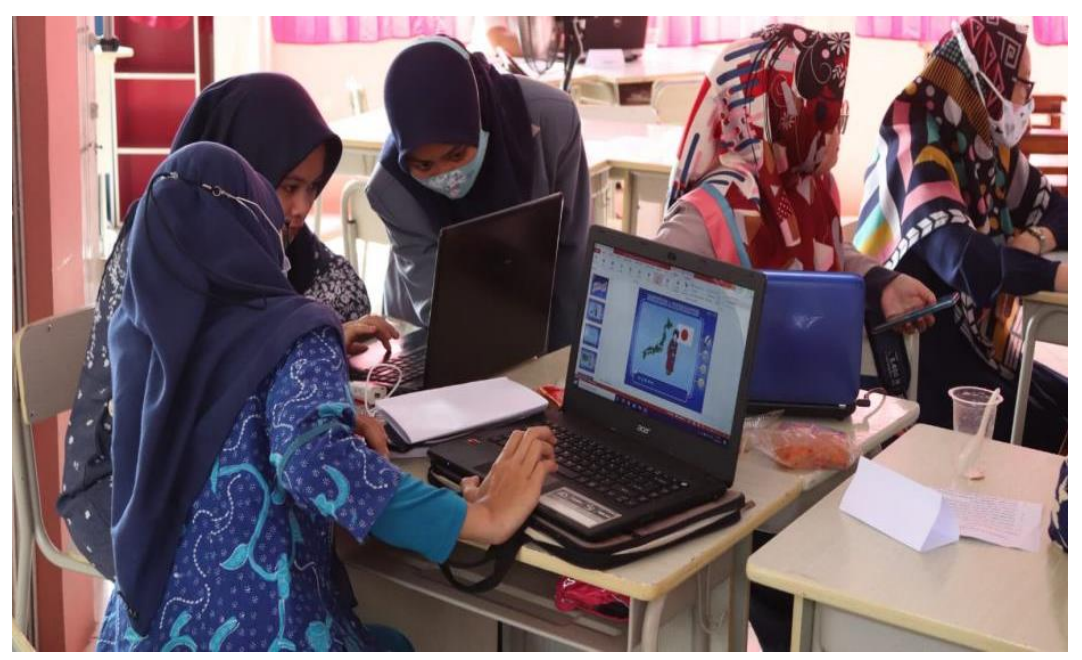

\section{Gambar 1. Aktivitas Peserta Praktik Membuat Karya Media Pembelajaran Interaktif}

Hasil perolehan rata-rata nilai pre test dibandingkan dengan rata-rata nilai pos test menunjukkan ada peningkatan, rata-rata pre test 54,74 dan rata-rata nilai post test mencapai 75,71 . Soal pre test dan post test mengukur pengetahuan guru tentang definisi, langkah-langkah pembuatan, penggunaan, dan manfaat media pembelajaran interaktif, serta konsep, jenis, dan isi LKPD interaktif. Dalam soal post test ditambahkan agar peserta menuliskan secara bebas kesan mengikuti lokakarya dan saran untuk tindak lanjut. Kesan yang diberikan peserta positif dan mengaku mendapat ilmu baru. Saran yang diberikan, memohon agar dilaksanakan lokakarya berikutnya satu kali setiap semester untuk diberikan pelatihan materi lain yang dibutuhkan untuk peningkatan kompetensi mereka.

\section{KESIMPULAN}

Berdasarkan hasil kegiatan lokakarya dapat disimpulkan bahwa guru-guru SDIT Insan Teladan selama PJJ-daring belum menggunakan media pembelajaran interaktif karena mereka belum memiliki pengetahuan dan keterampilan dalam pengembangan dan penggunaan media pembelajaran interaktif. Melalui pelaksanaan lokakarya guru-guru mengalami proses pelatihan membuat dan menggunakan media interaktif berbasis TIK dalam bentuk powerpoint interaktif, 
LKPD interaktif, dan video animasi powtoon dengan hasil memuaskan sebagaimana tercermin dari peningkatan rata-rata nilai posttest $(75,71)$ dibandingkan dengan rata-rata nilai pretest $(54,74)$. Berdasarkan kesan guru-guru yang ditulis dalam lembar postest, mereka mengakui mendapatkan ilmu baru dalam pembuatan dan penggunaan media pembelajaran interaktif serta mampu mengembangkan secara mandiri setelah terlatih membuat powerpoint interaktif, LKPD interaktif, dan video animasi powtoon.

\section{UCAPAN TERIMA KASIH}

Ucapan terima kasih disampaikan kepada Kepala SDIT Insan Teladan dan dewan guru yang telah bersedia menjalin kerjasama dengan Tim Pengabdian Dosen UPI Kampus Cibiru. Diharapkan pelaksanaan pengabdian ini tidak berakhir sebatas lokakarya pengembangan media pembelajaran interaktif tetapi berlanjut pada lokakarya yang berorientasi pada peningkatan kompetensi guru-guru SDIT Insan Teladan.

\section{DAFTAR PUSTAKA}

[1] Carolyn, M. 2013. "Memahami perkembangan anak." Penerjemah : Agnes Theodora W. Penyunting : Tim Indeks. PN Jakarta: Indeks.

[2] Sanaky,H. 2013. "Media Pembelajaran Interaktif-Inovatif." Yogyakarta:Kaukaba Dipantara. h.3 [3] S. Aljawarneh, M. Aldwairi, and M. B. Yassein, "Anomaly-based intrusion detection system through feature selection analysis and building hybrid efficient model," J. Comput. Sci., vol. 25, no. 1, pp. 152-160, 2018, doi: 10.1016/j.jocs.2017.03.006.

[4] Eusman. Kurniawan, D. dan Riyana, C. 2015. @Pembelajaran Berbasis Teknologi Informasi dan Informasi dan Komunikasi. Jakarta: Rajawali Press. h.170.

[5] Rusman. 2015. "Pembelajaran Berbasis Teknologi \& Informasi." Jakarta: Raja Grafindo Persada. h.60.

[6] Ramansyah (2016). "Pengembangan Multimedia Pembelajaran Interaktif Dengan Tema Pengenalan Huruf Hijaiyah Untuk Peserta Didik Sekolah Dasar." Jurnal Ilmiah Edutic/ Vol.3, No.1, November 2016. p-ISSN 2407-4489 e-ISSN2528-7303.

[7] Purwanti, dkk. Analisis Penggunaan Media Power Point dalam Pembelajaran Jarak Jauh pada Materi Animalia Kelas VIII. Journal of Biology Education Vol 3 No 2 (2020) halaman 158. E-ISSN 2656-3436/ P-ISSN 2615-3947 IAIN KUDUS. Tersedia online: http://journal.iainkudus.ac.id/index.php/jbe.

[8] Yuliansyah. 2018. Efektivitas Media Pembelajaran Powerpoint Berbasis Animasi Dalam Meningkatkan Motivasi Dan Prestasi Belajar. Jurnal Efisiensi - Kajian Ilmu Administrasi Edisi Agustus 2018, Vol. XV No. 2, ISSN 1412-1131, e-ISSN 2528-5750, h.24-32. https://media.neliti.com/media/publications/299755-efektivitas-media-pembelajaranpowerpoin-af8a2382.pdf.

[9] Ponza, Jampel, Sudarma (2018). Pengembangan Media Video Animasi Pada Pembelajaran Peserta didik Kelas IV Di Sekolah Dasar. Jurnal EDUTECH Universitas Pendidikan Ganesha.Vol. 6 No. (1) h. 9-19

[10] Wuryanti, U. dan Kartowagiran, B. https: //media. neliti.com/ media/ publications/ 123228-ID- pengembangan- media-video- animasi- untuk- pdfhttps:// media.neliti.com/media/publications/123228-ID-pengembangan-media-video-animasiuntuk-m.pdf.

[11] Hasibuan, M.SP. 2014. "Manajemen Dasar, Pengertian, dan Masalah." Jakarta: PT Bumi Aksara. h.85.

[12] Gibson, R. dan Miichell, M. 2010. "Bimbingan dan Konseling." Yogyakarta: Pustaka Pelajar. h. 567. 